\title{
The single-breath transfer factor for carbon monoxide and respiratory symptoms in a Norwegian community sample
}

\author{
I. Welle, G.E. Eide, P.S. Bakke, A. Gulsvik
}

Relationship between the single-breath transfer factor for carbon monoxide and respiratory symptoms in a Norwegian community sample. I. Welle, G.E. Eide, P.S. Bakke, A. Gulsvik. C) ERS Journals Ltd 1999.

ABSTRACT: Reduced single-breath transfer factors of the lung for carbon monoxide are seen in a number of conditions. The hypothesis of the present study was that selfreported respiratory symptoms differ in their prediction of $T \mathrm{~L}, \mathrm{CO}$ level in a general population in Norway.

A cross-sectional survey of a general population sample in Norway, made up of 1,275 subjects aged $18-73$ yrs, was conducted in $1987-1988$. The attendees $(84 \%$ response rate) filled in a questionnaire on respiratory symptoms and underwent standardized spirometric and $T \mathrm{~L}, \mathrm{CO}$ measurements and clinical examination. Associations between $T \mathrm{~L}, \mathrm{CO}$ and respiratory symptoms were assessed using multiple regression models. Tests for interaction were used to examine whether these associations varied with sex, age and smoking habits. Data from 1,221 subjects were analysed.

Both males and females who reported respiratory symptoms had significantly lower $T \mathrm{~L}, \mathrm{CO}$ after adjusting for age and height. In a multiple linear regression analysis of $T \mathrm{~L}, \mathrm{CO}$, adjusting for sex, age, height and smoking habits, the symptoms for which statistical significance was attained, were morning cough, chronic cough and breathlessness. However, only the breathlessness score was independently associated with the $T \mathrm{~L}, \mathrm{CO}\left(-\mathbf{0 . 4 2} \mathrm{mmol} \cdot \mathrm{min}^{-1} \cdot \mathrm{kPa}^{-1}\right.$ per breathlessness score unit) after adjusting for other respiratory symptoms, and the relationship was stronger in males than in females.

In this study, the strongest predictor for a decreased single-breath transfer factor of the lung for carbon monoxide was the presence of self-reported breathlessness, regardless of age, smoking habits and height.

Eur Respir J 1999; 14: 1320-1325.
Dept of Thoracic Medicine, University of Bergen, Bergen, Norway.

Correspondence: I. Welle Dept of Thoracic Medicine University of Bergen

N-5021 Bergen

Norway

Fax: 4755975149

Keywords: Breathlessness

community survey

epidemiology

respiratory symptoms

single-breath transfer factor of the lung

Received: September 251998

Accepted after revision July 111999
Measurements of the single-breath transfer factor of the lung for carbon monoxide $(T \mathrm{~L}, \mathrm{CO})$ is a unique means of noninvasively assessing pulmonary gas exchange. Reduced values may be seen in chronic obstructive lung disease, especially emphysema [1], and various types of fibrosis [2], whereas high values occur in polycythaemia [3] and pulmonary haemorrhage [4]. The measurement of the $T$ L,CO usually constitutes the second stage in the assessment of lung function, after spirometry has been performed $[5,6]$. TL,CO measurement is hypothesized to allow early detection of functional impairment of the lungs $[7,8]$. However, limited data are available regarding the relationship between $T \mathrm{~L}, \mathrm{CO}$ and the presence of respiratory symptoms. In a cross-sectional survey of a general population in Northern Italy, including 1,612 smokers and nonsmokers aged 20-64 yrs, VIEGI et al. [9] observed that the TL,CO was significantly different between subjects with and without respiratory symptoms. To the authors' knowledge, no data on the association between $T \mathrm{~L}, \mathrm{CO}$ and the presence of respiratory symptoms have been published for Northern Europe.

The hypothesis of the present analysis of a Norwegian community survey was that self-reported respiratory symptoms differ in their prediction of TL,CO. Furthermore, it was also of interest to assess how this relationship varied with sex, age and smoking habits.

\section{Subjects and methods}

\section{Study population}

The study was a two-phase cross-sectional community survey. The methods of selection and the characteristics of the population have been given in detail previously [10, 11]. Briefly, the first phase was conducted in 1985; a questionnaire was posted to a random sample of 4,992 subjects of the general population, aged 15-70 yrs and living in the county of Hordaland on the south-west coast of Norway. The response rate was $90 \%(n=4,469)$.

Based on the information obtained from the postal survey, the respondents living in Bergen or one of 11 surrounding municipalities $(n=3,370)$ were divided into two strata. The first stratum contained subjects who had received a physician's diagnosis of asthma and emphysema, those who had been occupationally exposed to asbestos or quartz and nonsmokers without respiratory symptoms. The second stratum contained those not included in the first [11]. In the second phase, conducted between April 1987 and July 1988, a 91\% random sample of the subjects in stratum 1 and a $22 \%$ random sample of the subjects in stratum 2, 1,512 subjects altogether, were invited to take part in a standardized clinical examination. The overall attendance rate was $84 \%$ of those invited [11]. 
The examination included completion of a questionnaire on respiratory symptoms, $T \mathrm{~L}, \mathrm{CO}$ and spirometric measurements, and a clinical examination.

\section{Respiratory symptoms and smoking habits}

Questions were worded as shown in table 1 [12]. The alternatives for answering the questions were yes and no. Subjects were considered asymptomatic if they answered negatively to all the questions, and symptomatic if at least one of the questions had been answered in the affirmative. A five-point breathlessness rating was defined, ranging, in order of increasing severity of breathlessness, from 0 (no breathlessness) to 4 (breathlessness at rest); thus, the higher the score, the worse the breathlessness.

According to their smoking habits, subjects were divided into three groups: nonsmokers, exsmokers and current smokers. Nonsmokers were defined as subjects who stated that they had never smoked daily. Exsmokers were those who had smoked on a daily basis, but who had given up prior to the survey. Current smokers were those who smoked on average at least one cigarette daily at the time of the study [13]. The amount of lifetime smoking was assessed in pack-yrs. This was calculated by multiplying the duration of smoking in yrs by the number of cigarettes smoked per day and dividing the product by 20 .

\section{Transfer factor test and spirometry measurements}

The equipment as well as the standardized procedure has been described in detail previously $[14,15]$. Measurements of TL,CO were made using a Gould 2100 automated system (Sensor Medics, Bilthoven, the Netherlands) and a gas mixture containing $10 \%$ helium, $0.3 \%$ carbon monoxide, $21 \%$ oxygen and a balance of nitrogen. The breathholding time was preset to $10 \mathrm{~s}$ and the washout volume to $0.75 \mathrm{~L}$. The dead space of the sample bag was $6.25 \mathrm{~mL}$ [14]. Each subject's height was measured in stockinged feet to the nearest centimetre. Weight was measured without shoes and with empty trouser pockets. Before the test was performed, each subject was instructed in all the

Table 1. - Respiratory symptom questionnaire questions

\begin{tabular}{ll}
\hline Question & Symptom group \\
\hline $\begin{array}{l}\text { Do you usually cough or clear } \\
\text { your throat in the morning? }\end{array}$ & Morning Cough \\
$\begin{array}{c}\text { Do you have phlegm when } \\
\text { coughing }\end{array}$ & Phlegm when coughing \\
$\begin{array}{c}\text { Do you cough for three months or } \\
\text { more altogether during the year? }\end{array}$ & Chronic cough \\
$\begin{array}{c}\text { Do you ever have wheezing in } \\
\text { your chest? }\end{array}$ & Wheezing \\
$\begin{array}{l}\text { Are you more breathless than } \\
\text { people of your own age when }\end{array}$ & Breathlessness grade 1 \\
$\begin{array}{c}\text { walking uphill? } \\
\text { Are you breathless when you } \\
\text { climb two flights of stairs at } \\
\text { an ordinary pace? }\end{array}$ & Breathlessness grade 2 \\
$\begin{array}{c}\text { Are you breathless when you } \\
\text { walk on level ground at an } \\
\text { ordinary pace? }\end{array}$ & Breathlessness grade 3 \\
\begin{tabular}{l} 
Are you breathless when at rest? \\
\hline
\end{tabular} & Breathlessness grade 4 \\
\hline
\end{tabular}

required manoeuvres. A poster showing the different respiratory phases was placed in front of the subject. After the subject had adapted to the mouthpiece, $\geq 4-5$ tidal volumes were recorded in order to determine a regular end-expiratory baseline. The subject was asked to exhale as far as possible, until the point that it was felt that the lungs had been completely emptied. Points that were emphasized included the importance of giving a sign when at maximal exhalation (residual volume), making a rapid maximal inhalation within 2-2.5 s to vital capacity, continuing to hold the breath for $10 \mathrm{~s}$ while relaxing against a closed glottis (assisted by the valve system), and exhaling rapidly $[14,16]$. The test was performed on the subject in a sitting position wearing a nose clip. Each subject performed up to four measurements in order to provide two error-free tests. A minimum interval of 4 min was required between each test. The method of JonEs and MEADE [17] for determining breath-holding time was used in this study.

Of the 1,275 subjects who underwent TL,CO measurements, data from 154 were excluded from further analysis for the following reasons: a leak in the sample bag occurring during the first 18 days of the study $(n=108)$; inability to hold breath for $10 \mathrm{~s}$ in at least two TL,CO measurements $(n=16)$, not fulfilling the reproducibility criterion of two tests being within $10 \%$ of each other $(n=25)$; and undergoing unsatisfactory spirometric measurements $(n=5)$. The reference equations for TL,CO (in $\mathrm{mmol} \cdot \mathrm{min}^{-1} \cdot \mathrm{kPa}^{-1}$ ) used in this analysis were derived from a segment of healthy subjects who had never smoked, taken from a randomly selected population from the south-western coast of Norway, and were as follows [14]: $T \mathrm{~L}, \mathrm{CO}$ (females) $=-4.93$ $+9.11=$ height (in $\mathrm{m}$ ) -0.043 age (in yrs); and $T \mathrm{~L}, \mathrm{CO}$ (males) $=-8.05+12.17$ height (in $\mathrm{m}$ ) -0.057 age (in yrs).

Spirometry was also performed using the Gould 2100 spirometer. The inspiratory and expiratory limbs of the spirometer were calibrated automatically with a 2.1 -L motordriven syringe before each examination. The volume calibration was verified each day with a 3-L Gould Model M-20 calibrating syringe (Sensor Medics), with emptying times ranging $0.5-6 \mathrm{~s}$ [14]. The variables recorded included forced vital capacity (FVC) and forced expiratory volume in one second (FEV1). Three technically satisfactory measurements were obtained, in which FVC was reproducible within $300 \mathrm{~mL}$. A technically satisfactory test met the lung function testing criteria of the European Coal and Steel Community [18].

A venous blood sample was drawn before the transfer test for determination of total haemoglobin and carboxyhaemoglobin concentrations (OSM3 Hemoximeter; Radiometer, Copenhagen, Denmark). Analyses with this instrument are based on measurements of the transmission of light through the sample at six wavelengths.

\section{Clinical examination}

The clinical examination aimed at determining whether or not the subjects had obstructive lung disease, i.e. bronchial asthma or chronic obstructive lung disease (COLD), using diagnostic criteria applied in a previous Norwegian survey [19]. Bronchial asthma was diagnosed in those with a history of attacks of shortness of breath at rest, with wheezing in the chest changing in severity over a short 
period of time, either spontaneously or after treatment. At least one typical attack had to have occurred within the previous 6 months. COLD was diagnosed in those with a history of chronic cough, phlegm when coughing, breathlessness or wheezing or both, and a ratio of FEV1 to FVC of $<0.7$ [11].

\section{Statistics}

Descriptive statistics were computed separately for females and males. To study the crude relationship between $T \mathrm{~L}, \mathrm{CO}$ and the presence/absence of respiratory symptoms, unadjusted means of TL,CO were first estimated for each symptom, separately for females and males. The values of $T \mathrm{~L}, \mathrm{CO}$ were then calculated as a percentage of the predicted value, using a prediction model based upon asymptomatic subjects who had never smoked [14], with respect to each grade of breathlessness. Finally, the TL,CO was regressed on the basis of age, sex, height, smoking habits, symptoms and breathlessness score using multiple linear regression analysis. Smoking habits were categorized according to the three groups mentioned earlier, and were analysed using the dummy variable technique. All analyses were performed using the Biomedical Data Package statistical software package (University of California, Berkeley, CA, USA) [20].

\section{Results}

The characteristics of the study population are shown in table 2. There were more current smokers and exsmokers among males than among females. Smoking consumption was approximately twice as high in males as in females (mean \pm SD) $8.4 \pm 12.4$ and $3.3 \pm 6.7$ pack-yrs respectively, current and exsmokers combined. All respiratory symptoms, with the exception of breathlessness, were slightly more often reported by males than females. The opposite tendency was noted for the symptoms of breathlessness, with $21 \%$ of the females reporting the symptom and only $14 \%$ of the males (table 2 ). In both males and females, subjects with respiratory symptoms had lower unadjusted TL,CO than subjects without (table 3). Except for breathlessness, the magnitude of the difference in TL,CO between those with and without each symptom ranged 6$13 \%$ in both sexes, being highest for morning cough and chronic cough, and lowest for wheezing. The difference in mean $T \mathrm{~L}$, CO between those with and without breathlessness grade 2 and breathlessness grade 3 was much higher in males (respectively 21 and $47 \%$ ) than in females (respectively 13 and 15\%). When comparing subjects with and without bronchial asthma, no difference in $T \mathrm{~L}, \mathrm{CO}$ was observed, in either males or females. Patients suffering from COLD had significantly lower unadjusted TL,CO than those without COLD (table 3), and a mean $20 \%$ pred fall in $T$ L,CO was noted in males versus $12 \%$ in females.

In males, the TL,CO (in \% pred) decreased significantly with increasing breathlessness score $(p<0.001)$ (fig. 1), whereas in females no such trend was observed.

In a multiple linear regression analysis of $T \mathrm{~L}, \mathrm{CO}$ adjusting for sex, age and height as well as smoking habits, the
Table 2. - Characteristics of the study population by sex

\begin{tabular}{|c|c|c|}
\hline & Females & Males \\
\hline Subjects $n$ & $43 \pm 545$ & $41 \pm 576$ \\
\hline Age yrs & 16 & 16 \\
\hline Height $\mathrm{cm}$ & $165 \pm 6$ & $178 \pm 7$ \\
\hline $\mathrm{Hb} g \cdot \mathrm{L}^{-1}$ & $13.7 \pm 9.4$ & $15.2 \pm 9.8$ \\
\hline $\mathrm{HbCO} \%$ total $\mathrm{Hb}$ & $15.4 \pm 12.8$ & $18.3 \pm 15.0$ \\
\hline$T \mathrm{~L}, \mathrm{CO}^{+} \mathrm{mmol} \cdot \mathrm{min}^{-1} \cdot \mathrm{kPa}^{-1}$ & $7.83 \pm 1.6$ & $10.9 \pm 2.4$ \\
\hline$\%$ pred & $102 \pm 14.6$ & $100 \pm 15.8$ \\
\hline$V \mathrm{~A} \mathrm{~L}$ & $5.42 \pm 0.76$ & $7.34 \pm 1.03$ \\
\hline \multicolumn{3}{|l|}{ Smoking habits \% } \\
\hline Nonsmokers & 63 & 46 \\
\hline Exsmokers & 13 & 23 \\
\hline Current smokers & 24 & 31 \\
\hline Smoking comsumption pack-yrs & $3.3 \pm 6.7$ & $8.4 \pm 12.4$ \\
\hline \multicolumn{3}{|l|}{ Symptom group $\%$} \\
\hline Asymptomatic & 55 & 55 \\
\hline Morning cough & 19 & 26 \\
\hline Phlegm when coughing & 15 & 23 \\
\hline Chronic cough & 7 & 10 \\
\hline Wheezing & 26 & 27 \\
\hline Breathlessness grade $0^{\S}$ & 24 & 31 \\
\hline Breathlessness grade $1^{*}$ & 10 & 7 \\
\hline Breathlessness grade $2 * *$ & 10 & 5 \\
\hline Breathlessness grade $3 * * *$ & 1 & 2 \\
\hline Breathlessness grade $4 * * * *$ & 0 & 0.3 \\
\hline \multicolumn{3}{|l|}{ Physician diagnosis \% } \\
\hline Bronchial asthma & 3 & 2 \\
\hline COLD & 5 & 5 \\
\hline
\end{tabular}

Data are presented as mean $\pm \mathrm{SD}$ or percentage. ${ }^{+}$: mean of two measurements; §: no breathlessness; *: breathlessness when walking up hills (excluding grades $2-4$ ); **: breathlessness when walking up stairs (excluding grades 3 and 4 ); ${ }^{* * *}$ : breathlessness when walking on ground (excluding grade 4$) ; * * * *$ : breathlessness at rest. Hb: haemoglobin; HbCO: carboxyhaemoglobin; TL,CO: single-breath transfer factor of the lung for carbon monoxide; VA: alveolar volume; COLD: chronic obstructive lung disease.

symptoms cough in the morning and chronic cough were still significantly associated with a reduced $T \mathrm{~L}, \mathrm{CO}$ whereas phlegm when coughing and wheezing were no longer significantly associated (table 4). Breathlessness was related to decreased TL,CO after adjusting for sex, age, height and smoking habits, and a greater reduction in $T \mathrm{~L}, \mathrm{CO}$ with increasing breathlessness score was found in males than in females (the regression coefficient in males being approximately five times that in females) (table 4). This analysis was then repeated excluding subjects with asthma and COLD: the breathlessness score remained significantly associated with $T \mathrm{~L}, \mathrm{CO}$ in males $(\mathrm{p}<0.01)$, but not in females $(\mathrm{p}=0.80)$.

Additional multiple linear regression analyses were performed including all the respiratory symptoms as well as sex, age, height, smoking habits, smoking consumption (in pack-yrs) and the concentrations of haemoglobin and carboxyhaemoglobin in the model (table 5). Breathlessness was the only symptom that remained significantly associated with TL,CO: the higher the breathlessness score, the lower the $T \mathrm{~L}, \mathrm{CO}$.

First-order interaction terms between the respiratory symptoms and sex, age and smoking habits respectively were then added one at a time to the multiple linear regression model presented in the upper part of table 5. Only the significant and borderline significant interaction terms 
Table 3. - Mean single-breath transfer factor of the lung for carbon monoxide $(T L, C O)$ by respiratory symptoms and by sex

\begin{tabular}{|c|c|c|c|c|c|c|}
\hline & \multicolumn{3}{|c|}{ Females } & \multicolumn{3}{|c|}{ Males } \\
\hline & $\begin{array}{l}\text { Symptom } \\
\text { present }\end{array}$ & $\begin{array}{c}\text { Symptom } \\
\text { absent }\end{array}$ & p-value & $\begin{array}{c}\text { Symptom } \\
\text { present }\end{array}$ & $\begin{array}{c}\text { Symptom } \\
\text { absent }\end{array}$ & p-value \\
\hline Morning cough & $7.31 \pm 1.78$ & $7.95 \pm 1.51$ & 0.0002 & $9.76 \pm 2.56$ & $11.15 \pm 2.26$ & $<0.0001$ \\
\hline Phlegm when coughing & $7.30 \pm 1.55$ & $7.93 \pm 1.57$ & 0.0007 & $10.23 \pm 2.74$ & $11.05 \pm 2.24$ & 0.0004 \\
\hline Chronic cough & $7.04 \pm 1.83$ & $7.89 \pm 1.55$ & 0.0011 & $9.66 \pm 2.66$ & $10.99 \pm 2.33$ & 0.0001 \\
\hline Wheezing & $7.50 \pm 1.69$ & $7.95 \pm 1.53$ & 0.004 & $10.32 \pm 2.41$ & $11.07 \pm 2.35$ & 0.0007 \\
\hline Breathlessness grade $1 *$ & $7.03 \pm 1.51$ & $8.03 \pm 1.56^{+}$ & $<0.0001$ & $9.70 \pm 2.13$ & $11.19 \pm 2.21^{+}$ & $<0.0001$ \\
\hline Breathlessness grade $2 * *$ & $7.05 \pm 1.57$ & $8.03 \pm 1.56^{+}$ & $<0.0001$ & $8.79 \pm 2.16$ & $11.19 \pm 2.21^{+}$ & $<0.0001$ \\
\hline Breathlessness grade $3 * * *$ & $6.85 \pm 2.92$ & $8.03 \pm 1.56^{+}$ & 0.097 & $5.92 \pm 1.69$ & $11.19 \pm 2.21^{+}$ & $<0.0001$ \\
\hline Breathlessness grade $4 * * * *$ & - & - & & $4.80 \pm 3.18$ & $11.19 \pm 2.21^{+}$ & 0.0001 \\
\hline Bronchial asthma & $7.82 \pm 1.66$ & $7.83 \pm 1.58$ & 0.98 & $11.08 \pm 2.44$ & $10.86 \pm 2.39$ & 0.76 \\
\hline COLD & $5.53 \pm 1.34$ & $7.96 \pm 1.48$ & $<0.0001$ & $7.38 \pm 2.45$ & $11.05 \pm 2.24$ & $<0.0001$ \\
\hline
\end{tabular}

Data are presented as mean $\pm \mathrm{SD}$ in $\mathrm{mmol} \cdot \mathrm{min}^{-1} \cdot \mathrm{kPa}^{-1}$. ${ }^{*}$ : mean of two measurements $(\mathrm{n}=1121)$; * breathlessness when walking up hills (excluding grades $2-4) ; * *$ : breathlessness when walking up stairs (excluding grades 3 and 4 ); ***: breathlessness when walking on ground (excluding grade 4$) ; * * * *$ breathlessness at rest; ${ }^{+}$: mean $T$ L,CO in those who report no breathlessness (grade 0). COLD: chronic obstructive lung disease.

are presented in the lower part of table 5 . A borderline significance was defined a priori as $\mathrm{p}<0.10$. Age interacted both with morning cough and phlegm when coughing, while smoking habits affected chronic cough. The interaction term breathlessness score and sex was associated with $T \mathrm{~L}, \mathrm{CO}$ at a probability level of $\mathrm{p}<0.01$.

All the significant and borderline significant interaction terms were then added to the multiple linear regression model at the same time. The only interaction terms that remained significantly related to $T \mathrm{~L}, \mathrm{CO}$ were chronic co$\mathrm{ugh} /$ smoking $(\mathrm{p}<0.02)$ and breathlessness/sex $(\mathrm{p}<0.01)$.

\section{Discussion}

This Norwegian community study showed that subjects reporting respiratory symptoms had lower $T \mathrm{~L}, \mathrm{CO}$ than those not reporting these symptoms. However, only breathlessness was independently associated with $T \mathrm{~L}, \mathrm{CO}$ after adjusting for sex, age, smoking habits, height and the other respiratory symptoms, and also after excluding subjects with obstructive lung disease. The relationship between

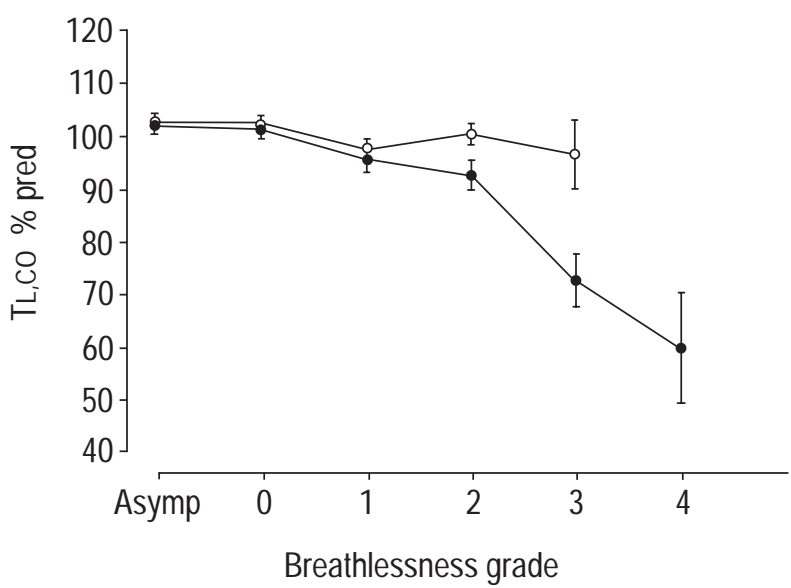

Fig. 1. - Single-breath transfer factor of the lung for carbon monoxide $(T \mathrm{~L}, \mathrm{CO})$ with respect to grade of breathlessness in males $(\mathbf{O}, \mathrm{n}=576)$ and females $(\bigcirc, n=545)$. Data are presented as mean $\pm \operatorname{SEM}(\mathrm{n}=1121)$. Asymp: asymptomatic. breathlessness and TL,CO was significantly stronger in males than in females. Chronic cough was more strongly related to $T \mathrm{~L}, \mathrm{CO}$ in smokers than in nonsmokers.

In the present study, $32 \%$ were not able to fulfill the criterion of an inspiratory vital capacity (IVC) $\geq 90 \%$ of FVC on TL,CO measurement. It has been recently advocated that data from these subjects should not be excluded from further analyses [15]. Rather, the IVC/FVC ratio obtained should be included in the analyses. When this was done in the present study, only slight changes were noted in the relationships between TL,CO and the respiratory symptoms. Furthermore, no changes were seen in the $T \mathrm{~L}, \mathrm{CO} /$ respiratory symptom associations when adjusting for the stratified sampling.

The independent relationship of $T \mathrm{~L}, \mathrm{CO}$ to breathlessness and not to the other respiratory symptoms may have several explanations. First, respiratory symptoms such as cough and phlegm may be related to other diseases of the upper airways that do not affect gas diffusing capacity.

Table 4. - Multiple linear regression of single-breath transfer factor of the lung for carbon monoxide with respect to each respiratory symptom adjusted for sex, age, height and smoking habits*

\begin{tabular}{|c|c|c|c|c|}
\hline & $\mathrm{r}$ & SEM & p-value & $\begin{array}{l}\text { p-value } \\
\text { interaction } \\
\text { with sex }\end{array}$ \\
\hline Morning cough & 0.3071 & 0.1151 & 0.01 & 0.12 \\
\hline $\begin{array}{l}\text { Phlegm when } \\
\text { coughing }\end{array}$ & 0.1355 & 0.1143 & 0.24 & 0.46 \\
\hline Chronic cough & 0.3116 & 0.1586 & 0.05 & 0.66 \\
\hline Wheezing & 0.1220 & 0.1020 & 0.23 & 0.98 \\
\hline \multicolumn{5}{|l|}{$\begin{array}{l}\text { Breathlessness } \\
\text { score }^{+}\end{array}$} \\
\hline Males & -0.7356 & 0.0936 & $<0.01$ & $<001$ \\
\hline Females & -0.1678 & 0.0874 & 0.06 & \\
\hline
\end{tabular}

*: $\mathrm{n}=1121 .{ }^{*}: \mathrm{p}$-value for the interaction term between sex and each of the respiratory symptoms; ${ }^{+}$: symptom score with increasing severity from breathlessness grade 0 (no breathlessness) to breathlessness grade 4 (breathlessness at rest), and defined as the highest breathlessness grade registered for each subject. 
Table 5. - Multiple linear regression of mean singlebreath transfer factor of the lung for carbon monoxide with respect to sex, age, height, smoking habits and respiratory symptoms*

\begin{tabular}{|c|c|c|c|}
\hline & $\mathrm{r}$ & SEM & p-value \\
\hline \multicolumn{4}{|c|}{ Main effects (no interaction term entered) } \\
\hline Intercept & -8.60 & & \\
\hline Male sex & 1.45 & 0.14 & $<0.01$ \\
\hline Age & -0.06 & 0.00 & $<0.01$ \\
\hline Height & 0.09 & 0.01 & $<0.01$ \\
\hline $\mathrm{Hb}$ & 0.03 & 0.00 & $<0.01$ \\
\hline $\mathrm{HbCO}$ & -0.03 & 0.00 & $<0.01$ \\
\hline \multicolumn{4}{|l|}{ Smoking habits } \\
\hline Exsmokers & -0.08 & 0.13 & \\
\hline Current smokers & -0.21 & 0.16 & \\
\hline $\begin{array}{l}\text { Smoking consumption } \\
\text { (in pack-yrs) }\end{array}$ & -0.02 & 0.006 & $<0.01$ \\
\hline Morning cough & 0.08 & 0.13 & 0.54 \\
\hline Phlegm when coughing & -0.14 & 0.12 & 0.24 \\
\hline Chronic cough & -0.07 & 0.17 & 0.69 \\
\hline Wheezing & -0.08 & 0.10 & 0.47 \\
\hline Breathlessness score & -0.40 & 0.07 & $<0.01$ \\
\hline \multicolumn{4}{|c|}{$\begin{array}{l}\text { Interaction terms that are significant and borderline signi- } \\
\text { nificant when entered separately in the above regression } \\
\text { analysis }\end{array}$} \\
\hline Morning cough/age & 0.01 & 0.01 & 0.06 \\
\hline $\begin{array}{l}\text { Chronic cough/smoking } \\
\text { habits }\end{array}$ & & & 0.02 \\
\hline Exsmokers & -1.113 & 0.40 & 0.02 \\
\hline Current smokers & -0.657 & 0.47 & \\
\hline $\begin{array}{l}\text { Breathlessness score/male } \\
\text { sex }\end{array}$ & -0.52 & 0.12 & $<0.01$ \\
\hline
\end{tabular}

*: $\mathrm{n}=1121$. Hb: haemoglobin; HbCO: carboxyhaemoglobin.

Breathlessness may be associated with diseases other than those of pulmonary origin, such as heart failure. However, cardiac insufficiency may also cause a reduced TL,CO [21]. Secondly, respiratory diseases affecting gas diffusion in the alveoli are more likely to cause breathlessness than respiratory diseases that only affect the central airways and cause cough and phlegm, such as bronchitis. Thirdly, that wheezing failed to predict independently the $T \mathrm{~L}, \mathrm{CO}$ could be due to this symptom's association with both bronchial asthma and COLD. Although COLD is characterized by low $T \mathrm{~L}, \mathrm{CO}[1]$, increased or normal $T \mathrm{~L}, \mathrm{CO}$ may be observed in patients with bronchial asthma [22]. The exact explanation for the normality or supernormality of $T \mathrm{~L}, \mathrm{CO}$ in asthmatics is not clear, but suggested mechanisms include overinflation, with alveolar recruitment enlarging the area of membrane available for diffusion, and an increase in pulmonary capillary volume, consequent to the more negative intrathoracic pressure required to overcome the increased airway resistance [23].

Lung function in terms of FEV1 is also found to be more strongly related to breathlessness than to cough and phlegm [12]. However, the association of dyspnoea with FEV1 is still weak. Several studies have shown that, in subjects with an FEV1 of 50-65\% pred, $40-50 \%$ report no dyspnoea $[24,25]$. In the present study, when the $T \mathrm{~L}, \mathrm{CO}$ was $<65 \%$ pred, $11 \%$ reported no dyspnoea, whereas $18 \%$ of those with an FEV1 of $<65 \%$ did not report this symptom.

It was observed that breathlessness was more strongly associated with TL,CO in males than in females. A cor- responding relationship by sex has been noted for the association of breathlessness with FEV1 $[12,19]$. VIEGI et al [9] found that $45 \%$ of the males with dyspnoea had abnormal $T \mathrm{~L}, \mathrm{CO}$ and/or $T \mathrm{~L}, \mathrm{CO} /$ alveolar volume indices, but only $7 \%$ of females showed such abnormalities. The interaction of breathlessness and sex in the association with TL,CO may have several explanations. First, there could be physiological differences between males and females in their perception of breathlessness, causing females to perceive dyspnoea at an earlier stage of respiratory disease than males [26]. Secondly, it may be speculated that males and females have different underlying pathophysiological mechanisms leading to the sensation of breathlessness. Breathlessness in females may be a more sensitive marker of poor health in general, but a less specific predictor for an underlying respiratory disorder, in comparison with breathlessness in males [26]. Thirdly, in Western societies, breathlessness is synonymous with bad physical condition as well as social disability, and is thus a factor restricting employment and success in social life, for example. Therefore, males may not wish to admit the presence of this symptom as often as females, in order to avoid being marked as "a symptomatic individual". This would consequently lead to a higher validity of breathlessness in males as a marker for decreased TL,CO. Males are also more frequently and more heavily occupationally exposed to airborne agents [10] that may impair gas diffusion and cause breathlessness.

In the present study, the relationship between chronic cough and decreased TL,CO was significantly stronger in current smokers and in exsmokers than in nonsmokers. The mechanisms causing chronic cough in current smokers may, to a greater extent than in nonsmokers, be related to reduced TL,CO. Reduced TL,CO is caused by not only defects in the alveolar capillary membrane but also disturbances in the ventilation/perfusion ratio of the lungs. Such a ventilation/perfusion mismatch may be more frequent in smokers than in nonsmokers. It is possible that the TL,CO is able to reflect early lung function changes related to minor anatomical modifications in subjects with chronic cough, especially in smokers [27].

Phlegm when coughing was significantly more strongly related to a reduced $T \mathrm{~L}, \mathrm{CO}$ in younger than in older people. In older subjects, phlegm when coughing may be partly ascribed to a slower clearing of ciliary mucus, not affecting the TL,CO. In younger subjects, this symptom may be an indicator of more specific physiopathological changes in the terminal airspaces (alveoli, alveolar ducts) leading to decreased $T \mathrm{~L}, \mathrm{CO}$.

Theoretically, the observed relationship between respiratory symptoms and reduced single-breath diffusing capacity of the lung for carbon monoxide could be driven by subjects with chronic obstructive lung disease. However, the relationship between single-breath diffusing capacity of the lung for carbon monoxide and respiratory symptoms remained significant even after excluding the subjects with chronic obstructive lung disease.

Thus, single-breath diffusing capacity of the lung for carbon monoxide measurements are able to differentiate between respiratory symptomatic and nonsymptomatic subjects in a general population sample. The long-term implications of a reduced single-breath diffusing capacity 
of the lung for carbon monoxide in subjects without obstructive lung diseases remains to be examined.

\section{References}

1. Thurlbeck W. Chronic airflow obstruction in lung disease. Philadelphia: Saunders WB; 1976.

2. Tukiainen P, Taskinen E, Holsti P, Korhola O, et al. Prognosis of cryptogenic fibrosing alveolitis. Thorax 1983; 38: 349-355.

3. Herbert S, Weill H, Stuckey W, Urner C, et al. Pulmonary diffusing capacity in polycythemic states before and after phlebotomy. Chest 1965; 48: 408-415.

4. Lipscomb D, Patel K, Hugues J. Interpretation of increase in the transfer coefficient for carbon monoxide $(T \mathrm{~L}, \mathrm{CO} / V \mathrm{~A}$ or KCO). Thorax 1978; 33: 728-733.

5. Cotes JE, Chinn DJ, Quanjer PH, Roca J, et al. Standardisation of the measurement of transfer factor (diffusing capacity). Report of working party. Standardisation of lung function tests, 1993 update. Eur Respir J 1993; 6: Suppl. 16, 41-52.

6. Cotes JE, Chinn DJ, Reed JW. Lung function testing: methods and reference values for forced expiratory volume and transfer factor. Occup Environ Med 1997; 54: 457-465.

7. Paoletti P, Viegi G, Pistelli G. Reference equations for the single-breath diffusing capacity. Am Rev Respir Dis 1985; 132: 806-813.

8. Teculescu D, Stanescu D. Lung diffusing capacity. Normal values in male smokers using the breath-holding technique. Scand J Respir Dis 1970; 51: 137-149.

9. Viegi G, Paoletti P, Prediletto R, Di Pede F, et al. Carbon monoxide diffusing capacity, other indices of lung function, and respiratory symptoms in a general population sample. Am Rev Respir Dis 1990; 141: 1033-1039.

10. Bakke P, Eide GE, Hanoa R, Gulsvik A. Occupational dust or gas exposure and prevalences of respiratory symptoms and asthma in a general population. Eur Respir $J$ 1991; 4: 273-278.

11. Bakke PS, Baste V, Hanoa R, Gulsvik A. Prevalence of obstructive lung disease in a general population: relation to occupational title and exposure to some airbome agents. Thorax 1991; 46: 863-870.

12. Gulsvik A, Bakke P, Humerfelt S, Omenaas E, et al. Measurements of respiratory symptoms and sample size to detect a given difference between treatment groups in obstructive lung disease. Eur Respir Rev 1991; 1: 436-443.

13. Bjartveit K, Foss O, Gjervig T. The cardiovascular diseases in Norwegian counties. Acta Med Scand 1983; 675: Suppl. 1: 1-184.
14. Gulsvik A, Bakke P, Humerfelt S, Omenaas E, et al. Single breath transfer factor for carbon monoxide in an asymptomatic population of never smokers. Thorax 1992; 47: 167-173.

15. Welle I, Eide GE, Bakke P, Gulsvik A. Applicability of the single-breath carbon monoxide diffusing capacity in a Norwegian community study. Am J Respir Crit Care Med 1998; 158: 1745-1750.

16. American Thoracic Society. Single breath carbon monoxide diffusing capacity (transfer factor): recommendations for a standard technique - 1995 update. Am J Respir Crit Care Med 1995; 152: 2185-2198.

17. Jones RS, Meade F. A theoretical and experimental analysis of anomalities in the estimation of pulmonary diffusing capacity by the single-breath method. $Q J \operatorname{Exp}$ Physiol 1961; 46: 131-143.

18. ECCS. European Community for Coal and Steel. Standardized lung function testing. Bull Eur Physiopathol Respir 1983; 19: Suppl. 5, 1-95.

19. Gulsvik A. Prevalence and manifestations of obstructive lung disease in the city of Oslo. Scand J Respir Dis 1979; 60: 286-296.

20. Dixon WJ. BMDP statistical software manual. Berkeley: University of California Press; 1985.

21. Siegel JL, Miller A, Brown LK, Deluca A, et al. Pulmonary diffusing capacity in left ventricular dysfunction. Chest 1990; 98: 550-553.

22. Macintyre N. Diffusing capacity of the lung for carbon monoxide. Respir Care Clin N Am 1997; 3: 221-233.

23. Stewart RI. Carbon monoxide diffusing capacity in asthmatic patients with mild airflow limitation. Chest 1988; 94: 332-336.

24. Boezen H, Schouten J, Postma D, Rijken B. Relation between respiratory symptoms, pulmonary function and peak flow variability in adults. Thorax 1995; 50: 121126.

25. Fletcher CM, Peto R, Tinker C, Speizer FE. The natural history of chronic bronchitis and emphysema. An eightyear study of early chronic obstructive lung disease in working men in London. Oxford: Oxford University Press; 1976.

26. Kauffmann F, Becklake M. Maladies respiratoires obstructives. Un paradigme de la complexité des differences de santé entre femmes et hommes. In: Saurel-Cubizolles M, Blondel B, eds. La santé des femmes. Paris: Flammarion, 1996. pp. 209-228.

27. Viegi G, Paoletti P, Vellutini M, Carrozi L, et al. Effects of daily cigarette consumption on respiratory symptoms and lung function in a general population sample of NorthItalian men. Respiration 1991; 58: 282-286. 